
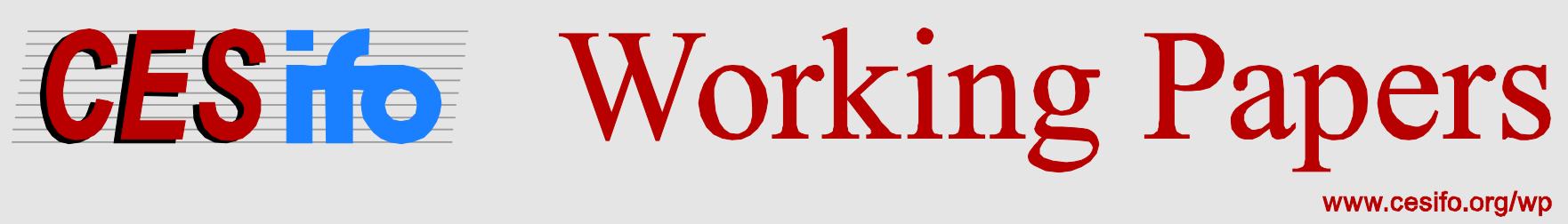

\title{
Using Output-Based Allocations to Manage Volatility and Leakage in Pollution Markets
}

\author{
Guy Meunier \\ Juan-Pablo Montero \\ Jean-Pierre Ponssard
}

CESIFO WORKING PAPER NO. 6334

CATEGORY 10: ENERGY AND CLIMATE ECONOMICS

JANUARY 2017

An electronic version of the paper may be downloaded

- from the SSRN website:

- from the RePEc website:

- from the CESifo website:

WwW.SSRN.com

www.RePEc.org

www.CESifo-group.org/wp 


\title{
Using Output-Based Allocations to Manage Volatility and Leakage in Pollution Markets
}

\begin{abstract}
Output-based allocations (OBAs) are typically used in emission trading schemes to mitigate leakage in sectors at risk. Recent work has shown they may also help to stabilize prices in markets subject to supply and demand shocks. We extend previous work to simultaneously include both leakage and volatility. Motivated by discussions on how to reform carbon markets around the world, and in Europe in particular, we use our model to revisit several critical issues in the design of these markets. In particular, we look at how different OBA schemes manage permit price uctuations and what are the implications of deducting OBA permits (the majority going to trade-exposed and carbon intensive sectors) from the overall permit allocation, so as to keep the global cap on emissions fixed (as it is the case in California and in the EU).
\end{abstract}

JEL-Codes: D240, L130, H230, L740.

Keywords: pollution markets, carbon price volatility, output-based allocations.

\author{
Guy Meunier \\ INRA-UR1303, ALISS \\ 65 Boulevard de Brandebourg \\ France - 94200 Ivry sur Seine \\ guy.meunier@ivry.inra.fr
}

\author{
Juan-Pablo Montero \\ Department of Economics \& \\ Center for Global Change \\ Pontificia Universidad Católica de Chile \\ (PUC-Chile) \\ Chile - Macul, Santiago \\ jmontero@uc.cl
}

\author{
Jean-Pierre Ponssard \\ Department of Economics \\ Ecole Polytechnique-CNRS \\ France - 91128 Palaiseau Cedex \\ jean-pierre.ponssard@polytechnique.edu
}

December 19, 2016

We thank seminar participants at the 2016 Atlantic Workshop in Energy and Environmental Economics at A Toxa for comments. Meunier and Ponssard also thank the financial support of the chair Energy and Prosperity, the Ecole Polytechnique - EDF chair for Sustainable Development, and ANR/Investissements d'avenir (ANR -11- IDEX-0003-02), and Montero of Fondecyt (Grant No. 1161802) and ISCI Institute (Basal FBO-16). 


\section{Introduction}

According to Ian Duncan, the conservative spokesperson for energy and climate change in the European Parliament "Right now the ETS is like a car without an engine" 11 Indeed for most of 2016 the carbon price has remained around $5 € /$ tCO2. At such low level, the quotation continues, "it cannot do the job it should and drive emissions reductions in Europe".

To provide firms with some regulatory certainty regulators need to fix the contractual rules of ETSs, including the cap, long in advance, say in 2005 for the EU-ETS covering the period 2013-2020, or in 2016 for the EU-ETS covering the period 2020-2030. Back in 2005, they were unable to anticipate the uncertainties, such as the severe and durable European recession in market conditions, the new supply fuel sources such as shale gas and their implication on the price of coal, as well the new regulations that were put in place to promote renewable energy production. The unfolding of these uncertainties made the cap committed in 2005 to look little ambitiious ex-post. Furthermore, EU regulators face numerous legal and political constraints that prevent them from updating their previous commitments.

The inability to provide a long term signal for investment decisions has thrown doubts on the efficiency of the EU-ETS and various proposals to mitigate the problem such as introducing a stability mechanism are currently examined $2^{2}$ The EU-ETS is not exceptional in its inability to deliver a reasonable sequence of prices. A similar experience had been observed for the SO2 market (Schmalensee et al., 1998; Schmalensee and Stavins, 2013). More recently, Borenstein et al. (2015) reviewed the rules in place for the California CO2 market and showed that it is quite likely that future carbon prices will jump from floor to ceiling of a predetermined price corridor, which had appeared quite large at the time it was set 3

This paper is motivated by an empirical observation related to the issue discussed above. The rules governing ETSs usually involves two ingredients: a given amount of permits is allocated through auctions while another amount is allocated for free to some industries such as cement, petrochemicals, steel. The reason advocated for the introduction of free allocations is to preserve the competitiveness of those industries from unregulated foreign competitors. This is known as the "leakage" problem and the economic literature has explored the benefit and cost of using free allocations to mitigate this problem. A second best recommendation

\footnotetext{
${ }_{1}^{1}$ http://www.bloomberg.com/news/articles/2016-05-31/faster-carbon-market-cuts-eyed-aseu-parliament-kicks-off-debate

${ }^{2}$ http://ec.europa.eu/clima/policies/ets/index_en.htm

${ }^{3}$ For more examples of unbinding caps in existing ETS see ?.
} 
often implemented in absence of border tax adjustments is to use the so-called "output based free allocations" (to be referred as OBA). In the EU-ETS the emissions from industries at risk of leakage represent approximately $40 \%$ of total emissions.5 Ex-post, it appeared that these industries received too much free allocations which, with the fixed cap, contributed significantly to the decline of the carbon price. In a way the introduction of OBA for industries at risk, while keeping the overall cap fixed, inherently lead to a higher volatility in the carbon price. From a policy standpoint, would it be a better idea to let the overall cap be flexible?

We shall address this question building on a recent paper of the authors (Meunier et al., 2016) in which it is demonstrated that, even in absence of leakage, there are good reasons to introduce OBA for sectors subject to large demand and supply shocks. From a welfare point of view, in absence of leakage but with uncertainty, the impact of using OBA can be understood using the price versus quantity framework introduced by Weitzman (1974). If regulators need to fix a cap in advance while firms make their decisions after the uncertainties unfold, two effects should be taken into consideration. On the one hand, output is subsidized which is undesirable from a social-welfare point of view, but on the other, the resulting carbon price may remain closer to marginal damage, which is desirable. In our previous paper we characterized these two effects and show that the second effect dominates, in particular when the ETS concerns several sectors subject to different supply and demand shocks.

In this paper we generalize our previous results when leakage is also present. We show that the larger the sector uncertainty, the higher the OBA rate for this sector should be. As a matter of fact, a large sector uncertainty should be considered as a factor as important as leakage for introducing OBA in that sector. This is an important and timely policy consideration since regulators are currently reviewing the allocation of free allocations in the EU-ETS for the period 2020-2030. Secondly, we use the model to explore numerically how different OBA schemes manage permit price fluctuations and what are the implications of deducting OBA permits (the majority going to trade-exposed and carbon intensive sectors) from the overall permit allocation so as to keep the global cap on emissions fixed (as it is the case in California and in the EU). Our numerical results show that an OBA scheme can significantly reduce carbon price fluctuation as long as its implementation considers a

\footnotetext{
${ }^{4}$ With an OBA scheme firms receive free allocations in proportion to their output, using an industry benchmark. Such schemes reduce the carbon pass through rate, which is good for preserving competitiveness, without affecting abatement decisions. For economic analysis of these schemes see Fischer and Fox (2007); Quirion (2009); Monjon and Quirion (2011); Fischer and Fox (2012); Meunier et al. (2014).

${ }^{5}$ In the EU-ETS the adopted scheme is an approximation of OBA in which the free allocations depend on the output relative to predefined thresholds (Branger et al., 2015).
} 
flexible cap on total emissions. Insisting on a fixed cap would only increase price fluctuations and induce severe welfare losses on non-OBA sectors (mainly electricity). Furthermore, the introduction of OBA permits together with a flexible global cap generate almost no distortion in these non-OBA sectors. All these results indicate that supply and demand shocks make a strong case for the use of OBAs, even more than leakage does.

The rest of the paper is organized as follows. The model is presented in Section 2. Policy simulations are in Section 3. We conclude in Section 4. Mathematical proofs are postponed to the Appendix.

\section{Model}

Consider an econonomy with two independent sectors, labeled $i=1,2$, each producing an homogenous good. The two sectors are covered by a common permit market, the functioning of which will be described shortly, and is the sole link between the two sectors. The total quantity consumed in sector $i$ is $q_{i}$, which is sum of home production $q_{i h}$ and foreign production $q_{i f}$. Consumer gross surplus in sector $i=1,2$ is given by $S_{i}\left(q_{i}, \theta_{i}\right)$, where $\theta_{i}$ is random shock, and the inverse demand function by $P_{i}\left(q_{i}, \theta_{i}\right)=\partial S_{i}\left(q_{i} ; \theta_{i}\right) / \partial q_{i}$. We assume that shocks $\theta_{1}$ and $\theta_{2}$ distribute according to the cummulative distribution function $F\left(\theta_{1}, \theta_{2}\right)$.

We assume that production, both at home and abroad, is carried out by a group of price-taking and identical firms. The cost at home in sector $i=1,2$ is given by $C_{i h}\left(q_{i}\right)$ and abroad by $C_{i f}\left(q_{i f}\right)$. The production of each unit, whether domestically or internationally, emit $\mathrm{CO}_{2}$ emissions at a rate that is normalized to one, so environmental harm is given by $D(e)$, where $e=q_{1}+q_{2}$ are total emissions.

Denoting by $\mathbf{q}$ the quantity-quadruple $\left(q_{1 h}, q_{2 h}, q_{1 f}, q_{2 f}\right)$, the social welfare function of the domestic regulator is given by

$$
W\left(\mathbf{q}, \theta_{1}, \theta_{2}\right)=\sum_{i=1,2}\left[S_{i}\left(q_{i h}+q_{i f}, \theta_{i}\right)-C_{i h}\left(q_{i h}\right)-C_{i f}\left(q_{i f}\right)\right]-D(e)
$$

Notice that in our welfare formulation foreign costs enter as if foreign plants were owned by home producers, very much like domestic plants. This assumption is made mainly for a methodological reason. It allows us to focus on the environmental incentive to regulate production and to ignore any incentive that the regulator may have to favor home production relative to foreign production. Second, we do not consider the foreign market and the possible change in foreign consumption induced by home regulation. Such a change would indeed 
affect world emissions and the magnitude of leakage.

\subsection{OBA regulation and market equilibrium}

In the absence of government intervention, the market equilibrium leads to too much pollution. To correct for this, the regulator implements a permit-market regulation where the total amount of permits may not be fixed but endogenous to output. The regulator auctions off $\bar{e}$ permits and in addition allocates permits to firms based on their output $]^{6}$ For each unit of output, a domestic firm in sector $i$ gets $\alpha_{i}$ permits for free, so the total amount of home pollution/permits is equal to

$$
e_{h}=\bar{e}+\alpha_{1} q_{1 h}+\alpha_{2} q_{2 h}
$$

In what follows, we will refer to $\alpha_{i}$ as the OBA rate of sector $i=1,2$.

The regulator first sets the quantity of auctioned permits and the OBA rates, then firms learn shocks $\theta_{i}$, after which they decide how much to produce and pollute anticipating the additional permits they will get for their output. Since the permit market is perfectly competitive, the auction clears at the price firms expect to trade permits in the secondary market. We denote this price by $r$. Thus, each firm at home takes $r$ and the output price $p_{i}$ as given and solves

$$
\max _{q_{i h}} p_{i} q_{i h}-C_{i h}\left(q_{i h}\right)-r\left(1-\alpha_{i}\right) q_{i h}
$$

while each firm abroad solves

$$
\max _{q_{i f}} p_{i} q_{i f}-C_{i f}\left(q_{i f}\right)
$$

leading to the first-order (equilibrium) conditions

$$
p_{i}=C_{i h}^{\prime}\left(q_{i h}\right)+\left(1-\alpha_{i}\right) r=C_{i f}^{\prime}\left(q_{i f}\right)
$$

Equilibrium prices $p_{i}$ and $r$ are obtained using the inverse demand function $p_{i}=P_{i}\left(q_{i} ; \theta_{i}\right)$ and the permit market constraint (2). Equilibrium productions are then a function of the regulatory variables and the demand states $\mathbf{q}^{e}\left(\bar{e}, \alpha_{1}, \alpha_{2}, \theta_{1}, \theta_{2}\right)$, so the expected welfare to be

\footnotetext{
${ }^{6}$ In principle, the $\bar{e}$ permits could also be allocated for free to firms based, for example, on historic emissions. But as soon as we allow for some positive cost of public funds (Goulder et al., 1997), auctioning becomes optimal. Our implicit assumption in the article is that the cost of public funds is positive but arbitrarily small, so we do not need to explicitly model it.
} 
maximized by the (domestic) regulator is

$$
\hat{W}\left(\bar{e}, \alpha_{1}, \alpha_{2}\right)=\mathbb{E} W\left(\mathbf{q}^{e}, \theta_{1}, \theta_{2}\right)
$$

\subsection{Optimal design in the absence of uncertainty}

It is useful to consider first the case where shocks $\theta_{1}$ and $\theta_{2}$ are either absent or perfectly anticipated by the regulator. If the regulator could control production both at home and abroad, the first-best allocation is the quadruple $\mathbf{q}^{*}\left(\theta_{1}, \theta_{2}\right)=\left(q_{1 h}^{*}, q_{2 h}^{*}, q_{1 f}^{*}, q_{2 f}^{*}\right)$ that satisfies the usual first-order conditions

$$
P_{i}\left(q_{i h}+q_{i f}\right)-C_{i j}^{\prime}\left(q_{i j}\right)=D^{\prime}(e)
$$

for $i=1,2$ and $j=h, f$. However, the regulator can only control domestic production, in which case the second-best is given by

$$
P_{i}\left(q_{i h}+q_{i f}\right)-C_{i h}^{\prime}\left(q_{i h}\right)=D^{\prime}(e)\left(1+\frac{\partial q_{i f}}{\partial q_{i h}}\right)
$$

for $i=1,2$ and where $\partial q_{i f} / \partial q_{i h}$ is known as the leakage rate, which represents the increase in foreign production that results from a small reduction in home production. Using the equilibrium condition $P_{i}\left(q_{i h}+q_{i f}\right)=C_{i f}^{\prime}\left(q_{i f}\right)$, the leakage rate can also be expressed as

$$
l_{i}=-\frac{\partial q_{i f}}{\partial q_{i h}}=-\frac{P_{i}^{\prime}}{C_{i f}^{\prime \prime}-P_{i}^{\prime}}
$$

The second-best solution in (6) can be implemented with a permit regulation that considers positive OBA rates as described in the following Proposition.

Proposition 1 In the absence of uncertainty, the optimal permit scheme consists in setting $O B A$ rates equal to leakage rates

$$
\alpha_{i}=l_{i}
$$

and the quantity of auctioned permit $\bar{e}$ such that the equilibrium permit price is equal to marginal environmental damages

$$
r=D^{\prime}(e)
$$

where $e=\bar{e}+\alpha_{1} q_{1 h}+\alpha_{2} q_{2 h}+q_{1 f}+q_{2 f}$.

This result establishes a welfare rationale for the implementation of OBA. To understand this result, consider unregulated foreign production as a function of domestic production 
$q_{i f}\left(q_{i h}\right)$. Then, it is as if there is a positive externality associated to home production equal to $-D^{\prime}(e) \partial q_{i f} / \partial q_{i h}=l_{i} \times r$, in addition to the negative externality associated to total emissions. Therefore, the permit price corrects for the negative externality and the OBA rates work as subsidies that correct for this positive externality.

The influence of any regulatory variable on welfare can be decomposed as follows

$$
\begin{aligned}
d W & =\sum_{i}\left[\left(1-\alpha_{i}\right) r-\left(1-l_{i}\right) D^{\prime}(e)\right] d q_{i h} \\
& =\left(r-D^{\prime}(e)\right) d e_{h}-\sum_{i}\left[\alpha_{i} r-l_{i} D^{\prime}(e)\right] d q_{i h}
\end{aligned}
$$

where $d e_{h}=d q_{1 h}+d q_{2 h}$. The first line adds the benefits and costs associated to the changes of each sector home production. The benefit is equal to the permit price corrected by the OBA rate and the cost is the marginal environmental damage corrected by the leakage rate.

With the present model, there are two quantities, $q_{1 h}$ and $q_{2 h}$, indirectly controlled by three regulatory variables: $\bar{e}, \alpha_{1}$ and $\alpha_{2}$. Then, there is one degree of freedom and one can possibly set one of the OBA rates equal to zero and then adjust the other OBA rate and the permit price.

Corollary 1 In the absence of uncertainty, the second-best permit scheme can be implemented by any pair of $O B A$ rates that satisfy

$$
\frac{1-\alpha_{2}}{1-\alpha_{1}}=\frac{1-l_{2}}{1-l_{1}}
$$

and a quantity of auctioned permits such that the expected permit price is equal to the marginal environmental damage corrected by sector 1 leakage rate:

$$
r=\frac{1-l_{1}}{1-\alpha_{1}} D^{\prime}(e)
$$

Proof. It can be directly seen by plugging the above expressions into the expression (9) of the derivative of welfare.

\subsection{Optimal design under uncertainty}

In presence of uncertainty, the regulator must set the OBA rate and the quantity of auctioned permits ex-ante, before shocks $\theta_{1}$ and $\theta_{2}$ are realized. In such a case the two OBA rates will differ from the leakage rates because OBA rates play an additional role now. As documented 
by Meunier et al. (2016), they also offer the possibility to partially index the total cap to actual realization of demand, which vary period after period. However, this indexing comes at a price since the introduction of a wedge between OBA and leakage rates introduces an inefficiency. The total cap is no longer optimally allocated between the two sectors.

As it could be seen from the welfare expression (10), if the OBA rates are equal to the leakage rates (assume these do not depend on the demand states), in each demand state the discrepancy between the actual cap and the optimal one is reflected in the difference between the permit price and the marginal environmental damage. Welfare could be improved by relaxing (resp. strengthening) the cap when the former is higher (resp. lower) than the latter. An adjustment of the OBA rates can help in that direction.

Proposition 2 With uncertainty, the optimal permit scheme involves a quantity of auctionned permits and $O B A$ rates that satisfy:

$$
\begin{aligned}
\mathbb{E}\left[r-D^{\prime}(e)\right] & =\mathbb{E}\left[D^{\prime}(e) \sum_{i}\left(\alpha_{i}-l_{i}\right) \frac{\partial q_{i h}^{e}}{\partial \bar{e}}\right] \\
\mathbb{E}\left[\left(r-D^{\prime}(e)\right) q_{i h}\right] & =\mathbb{E}\left[D^{\prime}(e) \sum_{j=1,2}\left(\alpha_{j}-l_{j}\right) \frac{\partial q_{j h}^{e}}{\partial \alpha_{i}}\right]
\end{aligned}
$$

for $i=1,2$.

Proof. For the first equation (11), starts from equation 10 and use the relationship :

$$
\frac{\partial e_{h}}{\partial \bar{e}}=1+\sum_{i} \alpha_{i} \frac{\partial q_{i h}^{e}}{\partial \bar{e}}
$$

so that

$$
\frac{\partial \hat{W}}{d \bar{e}}=\mathbb{E}\left\{\left(r-D^{\prime}(e)\right)+\sum_{i}\left[\alpha_{i}\left(r-D^{\prime}(e)\right)-\left(\alpha_{i} r-D^{\prime}(e) l_{i}\right)\right] \frac{\partial q_{i h}^{e}}{\partial \bar{e}}\right\}
$$

and equation 11 follows.

Equation (12), on the other hand, comes from the optimal choice of the OBA rates and is obtained through a similar manipulation using the relationship for $k=1,2$ :

$$
\frac{\partial e_{h}}{\partial \alpha_{k}}=q_{k h}+\sum_{i}\left[\alpha_{i} \frac{\partial q_{i h}^{e}}{\partial \alpha_{k}}\right]
$$

An increase in the OBA rate of sector $i$ has the direct effect of releasing $q_{i h}$ permits in the market, which creates a marginal benefit and an environmental damage (left hand side 
of equation (12). It also indirectly influences production by increasing the subsidy to the sector under consideration and modifying the permit price. Such changes are captured in the right-hand side of equation (12). An increase in production in a sector is detrimental if the OBA rate is above the leakage rate, because production in such a case is already high.

To see the possible benefit of setting OBA rates away from leakage rates, we can evaluate a marginal change from the situation where both rates are equal. Setting $\alpha_{i}=l_{i}$ on the right hand side of equations (11) and (12), we see no gains from such marginal change if there is no correlation between the permit price and home output quantities. Otherwise, OBA and leakage rates can differ in order to take advantage of an non-null correlation to increase (resp. decrease) the total cap when the permit price is above (resp. below) the marginal environmental damage.

At the optimal scheme, if OBA and leakage rates differ, the quantity of auctioned permits should be adjusted. The optimal quantity is such that the expected difference between the permit price and the marginal environmental damage is equal to the inefficiency cost due to the difference between the OBA and leakage rates.

\subsection{Uncertainty with a quadratic specification}

To perform some simulations and better grasp the consequences of introducing uncertainty, a quadratic framework is developed. Let us consider linear environmental damages, quadratic production costs, and linear demand functions:

$$
\begin{aligned}
D^{\prime}(e) & =h \\
C_{i j}\left(q_{i}\right) & =\gamma_{i j} q_{i}^{2} / 2 \\
P_{i}\left(q_{i}, \theta_{i}\right) & =a_{i}+\theta_{i}-b_{i} q_{i}
\end{aligned}
$$

with $\left.\mathbb{E}\left[\theta_{i}\right]=0, \mathbb{E}\left[\theta_{i}^{2}\right]=\sigma_{i}^{2}, \mathbb{E}\left[\theta_{1} \theta_{2}\right]=\sigma_{12}\right]^{7}$ and for $i=1,2$ and $j=h, f$. The leakage rate is then independent of the demand state and equal to the ratio:

$$
l_{i}=\frac{b_{i}}{b_{i}+\gamma_{i f}}
$$

Let us denote by

$$
s_{i} \equiv \frac{1}{b_{i}\left(1-l_{i}\right)+\gamma_{i h}}
$$

\footnotetext{
${ }^{7}$ To ensure interior solutions we assume that $\sigma_{12}<h^{2}$. Assuming otherwise may lead to the creation of two sector-specific ETSs.
} 
the inverse of the slope of net surplus in sector $i$ with respect to home production after taking into account the adjustment of foreign production ${ }^{8}$ which could be interpreted as the market size at home.

Lemma 1 For any couple of $O B A$ rates $\left(\alpha_{1}, \alpha_{2}\right)$ the quantity of auctioned permits $\bar{e}$ that maximizes welfare is

$$
\bar{e}\left(\alpha_{1}, \alpha_{2}\right)=\sum_{i}\left(1-\alpha_{i}\right)\left(1-l_{i}\right) s_{i}\left(a_{i}-h\right)
$$

and the expected permit price is

$$
\mathbb{E} r=\frac{\sum_{i}\left(1-\alpha_{i}\right)\left(1-l_{i}\right) s_{i}}{\sum_{i}\left(1-\alpha_{i}\right)^{2} s_{i}} h
$$

If $O B A$ rates are set to zero, i.e., $\alpha_{1}=\alpha_{2}=0$, the optimal expected permit price is

$$
\mathbb{E} r=h\left(1-\frac{l_{1} s_{1}+l_{2} s_{2}}{s_{1}+s_{2}}\right)
$$

Without OBAs, the presence of leakage implies an optimal expected permit price lower than the marginal environmental damage (the same would be true with a tax). The wedge could be interpreted as a subsidy on production to correct for the leakage positive externality. This indirect subsidy is equal to the marginal environmental damage times an aggregated leakage rate. OBA rates allow to set sector specific subsidies that are more efficient.

As can be seen from equation (15), if OBA rates are set equal to the leakage rates, so that the leakage externality is well internalized, the optimal expected permit price should be equal to the marginal environmental damage. However, because of uncertainty, there is a gain to set OBA rates otherwise as the next proposition shows.

Proposition 3 Under the specification (13) above, an optimal permit scheme satisfies:

1. If $\left(1-l_{2}\right)^{2} s_{2}\left(\sigma_{2}^{2}-\sigma_{12}\right)=\left(1-l_{1}\right)^{2} s_{1}\left(\sigma_{1}^{2}-\sigma_{12}\right)$, then uncertainty does not influence the structure of the scheme and $\left(1-\alpha_{2}\right) /\left(1-l_{2}\right)=\left(1-\alpha_{1}\right) /\left(1-l_{1}\right)$ holds.

2. If $\left(1-l_{2}\right)^{2} s_{2}\left(\sigma_{2}^{2}-\sigma_{12}\right)>\left(1-l_{1}\right)^{2} s_{1}\left(\sigma_{1}^{2}-\sigma_{12}\right)$ the relative difference between the OBA

\footnotetext{
${ }^{8}$ Formally, by an implicit theorem argument, the derivative of net consumer surplus is (dropping $\theta_{i}$ )

$$
\frac{d^{2}}{d q_{i h}^{2}}\left[S_{i}\left(q_{i h}+q_{i f}\left(q_{i h}\right)\right)-C_{i h}-C_{i f}\right]=\frac{d}{d q_{i h}}\left[P_{i}-C_{i h}^{\prime}\right]=-\left[b_{i}\left(1-l_{i}\right)+\gamma_{i h}\right]
$$
}


rate and the leakage rate is larger in sector 2 than in sector 1 :

$$
\frac{\alpha_{2}-l_{2}}{1-l_{2}}>\frac{\alpha_{1}-l_{1}}{1-l_{1}} \geq 0
$$

so, by setting $\alpha_{1}=l_{1}$, the optimal OBA rate in sector 2 becomes larger than $l_{2}$ and equal to

$$
\alpha_{2}^{*}=1-\frac{1-l_{2}}{2}\left[\left(\Delta^{2}+4 \frac{\left(1-l_{1}\right)^{2} s_{1}}{\left(1-l_{2}\right)^{2} s_{2}}\right)^{1 / 2}-\Delta\right]>l_{2}
$$

where

$$
\Delta=\frac{1}{1-\sigma_{12} / h^{2}}\left\{\left(\frac{\sigma_{2}^{2}}{h^{2}}-1\right)-\frac{\left(1-l_{1}\right)^{2} s_{1}}{\left(1-l_{2}\right)^{2} s_{2}}\left(\frac{\sigma_{1}^{2}}{h^{2}}-1\right)\right\}
$$

The proof is in Appendix A. With uncertainty, OBA rates should differ from leakage rates. The relative difference is larger for sectors that are larger and riskier. The variability in those sectors is the main source of variations of the permit price, and there is a strong correlation between their output and the permit price. Such a correlation calls for an increase of the OBA rate since it helps releasing more permits precisely when the permit price is larger. And having a positive covariance $\left(\sigma_{12}>0\right)$ calls for an even larger OBA rate in sector 2 . To understand this latter, consider a situation in which there is no leakage and $\theta_{2}=\eta+\theta_{1}$, where $\eta$ is a shock specific to sector 2. If $\eta=0$, we know it is optimal to set $\alpha_{1}=\alpha_{2}=0$. But if $\eta>0$, there will be a positive correlation between $r$ and $q_{2}$, which calls for an increase of $\alpha_{2}$. But doing so introduces an asymmetry in the response to the common shock $\theta_{1}$. With $\alpha_{2}>0$, a positive shock $\theta_{1}$ leads to an increase of $q_{2}$ and a decrease of $q_{1}$, since sector 2 is less sensitive to a change in the permit price, precisely because of $\alpha_{2}>0$. This implies that any increase in the covariance $\sigma_{12}$ (or, in this example, the variance of the common shock $\left.\theta_{1}\right)$ calls for a further increase of the optimal OBA rate $\alpha_{2}$.

\section{$3 \quad$ Simulation and policy implications}

In this section we use our model to analyze the consequences of introducing an OBA scheme in permit-trading regulation and discuss its policy implications using a numerical illustration. We take the carbon market in Europe, better known as the EU-ETS, as a background for this discussion. In this context it is important to note that the regulatory decisions are made much in advance: elaborated around 2007-2008 for phase III 2013-2020, around 2016-2017 for phase IV 2021-2030. In the EU-ETS phase III a piece-wise approximation of OBA had been introduced for sectors at risk of leakage while all remaining sectors will receive no free 
(OBA) allowances or a decreasing lump sum (Branger et al., 2015). Our static model thus refers to the duration of a whole phase, and to the uncertainties as anticipated or not so much time in advance. While some adaptations are contemplated for phase IV none was considered for phase III.9

The first issue we address concerns the difficult question of defining the sectors at risk, i.e., the sectors that should be entitled to OBA permits. Initially to be eligible for OBA permits, the EU-ETS required a sector to simultaneously exhibit a carbon intensity and exposition to international trade above pre-established thresholds. In the end it required the sector to comply with either requirement. As a result, more than $80 \%$ of industrial emissions (i.e., emissions covered by the EU-ETS except electricity production) became eligible for OBA permits. This has taken the EU to revise its eligibility criteria. A tiered approach is considered in which the sector OBA rate would depend on the level of leakage in that sector. Our results suggest that sector-level uncertainty is also a relevant criteria for introducing OBAs.

The second issue we consider is whether the flexibility in emissions induced by granting OBA permits to some sectors should necessarily lead to some flexibility in the overall home cap, as formulated in our analysis. Under the current EU-ETS regulation the total home cap over the period is fixed (and declining over time at a constant yearly rate). The current level of activity has dropped significantly post the commitment set in a context of high economic activity, so all sectors have emissions much lower than was originally expected. This partly explains the drop observed in the carbon price and the current debate on how to eliminate the "excess" of allowances in the market 10 We will show that a flexible total cap would have mitigated this unbalance greatly; furthermore, it would have reduced perverse effects in non-OBA sectors (i.e., sectors for which $\alpha=0$ ) due to the drop in the carbon price.

\subsection{A numerical illustration}

The illustration that follows is based on the quadratic specification of section 2.4 with two sectors with the following numerical values for the parameters: $a_{1}=a_{2}=1, b_{1}=b_{2}=1$, $\gamma_{1 h}=1, \gamma_{1 f}=+\infty$ (no foreign competitors in sector 1$), \gamma_{2 h}=1, \gamma_{2 f}=3, h=1 / 4, \theta_{1}=0$ and $\theta_{2} \in\{-\lambda, \lambda\}$ with equal probability, so $\sigma_{2}=\lambda$. The parameter $\lambda$ will be referred as the level of uncertainty or volatility. The model is explored for $\lambda$ moving from 0 to $1 / 2$. We

\footnotetext{
${ }^{9}$ http://www . europarl . europa.eu/sides/getDoc.do?type=IM-PRESS\&reference= 20161215IPR56370\&language=EN\&f ormat=XML

${ }^{10}$ http://ec.europa.eu/clima/policies/ets/index_en.htm
} 
are particularly interested in large values of $\lambda 11$ We also interested in different values of $\gamma_{2 f}$ to cover different leakage rates for sector 2 . While in this illustration the leakage rate is independent of the level of uncertainty, i.e., $l_{2}=1 /\left(1+\gamma_{2 f}\right)$, the optimal OBA rate, which can be obtained using Proposition 2, is not.

We turn to the first issue. Figure 1 depicts the dependence of the optimal OBA rate on the level of uncertainty for a given value of $l_{2} \in\{0,1 / 4,1 / 2\}$, allowing $\gamma_{2 f}$ to vary accordingly. It shows that the optimal OBA rate increases significantly with sector uncertainty. The respective influence of the leakage rate and the level of uncertainty on the optimal OBA rate varies. For low levels of uncertainty the leakage rate is the main factor behind the optimal OBA rate, but as uncertainty increases the leakage rate becomes less of a factor to virtually disappear for large levels of uncertainty. Figure 2 shows welfare losses in percentage terms when implementing OBA without paying attention to uncertainty for the same three levels of leakage. As expected, welfare losses are greater the lower the leakage rate and the higher the level of uncertainty. According to our model, it is recommended to use a tiered taxonomy based on the sector leakage and uncertainty rates, i.e., a sector with low leakage and high uncertainty would be eligible for a similar level Fixed Cap, of free OBAs as a sector with high leakage and low uncertainty.

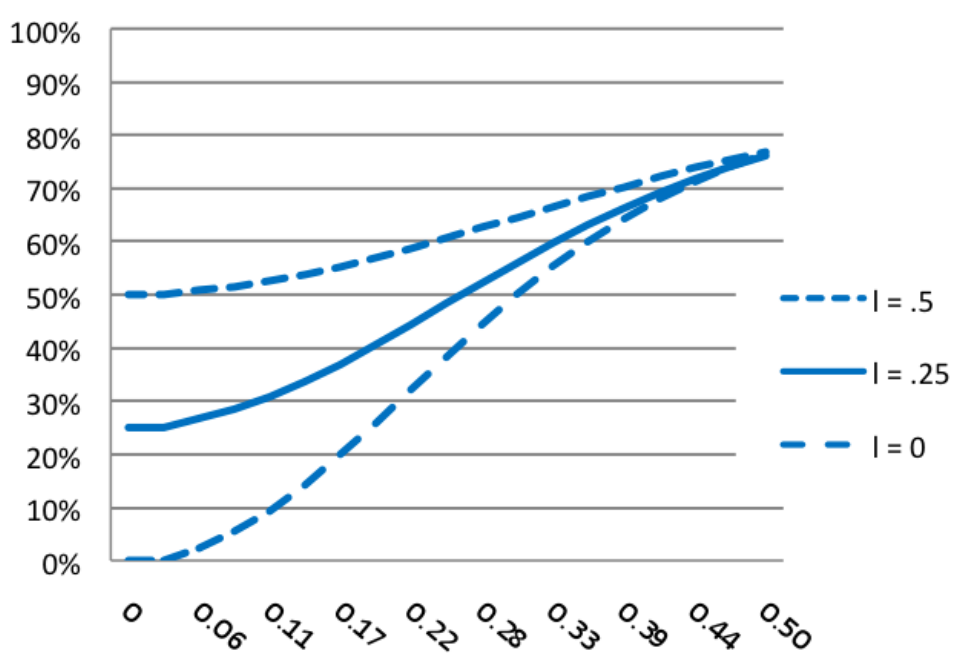

Figure 1: Optimal OBA rate as a function of uncertainty $(\lambda)$ for three leakage rates

\footnotetext{
${ }^{11}$ Take the cement market to have some order of magnitude for the level of uncertainty in a given sector. In Branger et al. (2015) it is observed that approximately $50 \%$ of the EU cement market has gone through a severe recession. In countries such as Ireland, Spain and Greece the level of cement consumption in 2012 was around $70 \%$ below the corresponding level of 2007, the time at which the EU-ETS had been designed. In our simulation we consider a range for the uncertainty factor of plus or minus $50 \%$, that is a drop of $80 \%$ in consumption relative to the peak.
} 


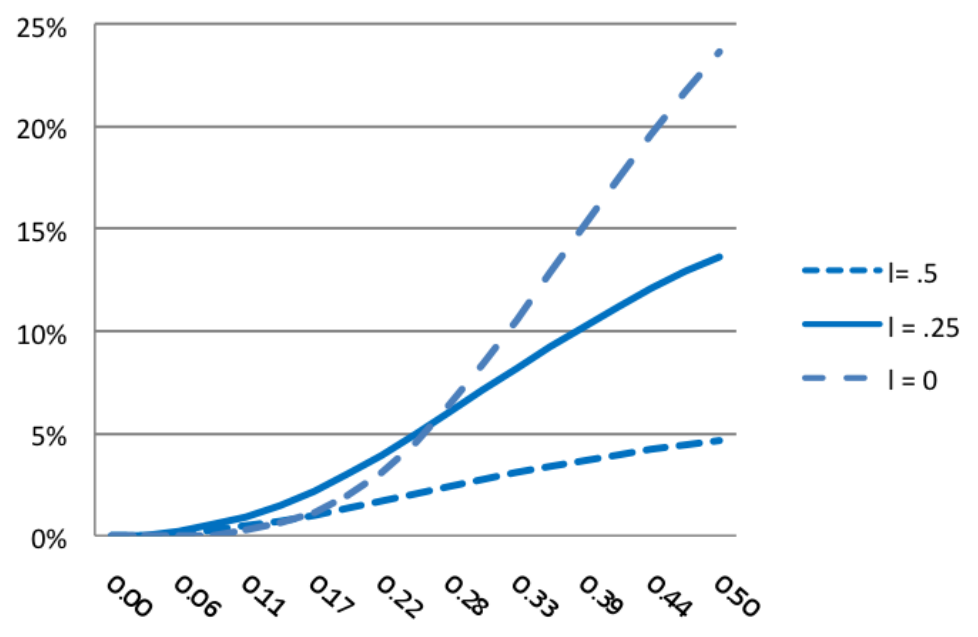

Figure 2: Welfare losses as a function of $\lambda$ of OBA rate at $\alpha_{2}=l_{2}$ vs optimal OBA rate $\alpha_{2}^{*}$

Consider now the second issue. For this discussion we set $\gamma_{2 f}=3$ so that $l_{2}=1 / 4$. We compare two scenarios. In the first one, Flexible Cap, the total cap at home is flexible and determined endogenously by our optimal policy. In the second one, the total cap is kept constant, i.e., any increase (or reduction) of emissions in sector 2 is compensated with an equal reduction (or increase) of auctioned permits so that total emissions at home (but not necessarily abroad) remain constant. This second scenario corresponds the current practice in cap-and-trade systems in Europe and in California, where any current year's increase/reduction in the cap is compensated with an equivalent reduction/increase in a future year.

For comparing these two scenarios we use as benchmarks either a first best scenario (i.e. a world tax equal to the marginal damage) or a fixed cap scenario in which there are no OBA.

The results are summarized Table 1 . They corresponds to a level of uncertainty $\lambda=0.5$. In both scenarios the OBA rate in sector 2 is the optimal one for scenario Flexible Cap. Adjusting this rate for scenario Fixed Cap would only slightly change the results. The introduction of OBA induces an increase in the expected home emissions relative to a fixed cap scenario but it reduces the welfare loss relative to the first best. As is well known the introduction of OBA induces a transfer in welfare from the non OBA sector 1 to the OBA sector 2 in the case of a fixed cap. Observe that that this is no longer true with a flexible cap: indeed the welfare in sector 1 increases and the loss in sector 2 is reduced. The profit of sector 1 is less affected with a flexible cap than with a fixed cap. The gains from OBA in 
sector 2 relative to the non OBA case are more substantial with a flexible cap than with a fixed cap. The flexible cap scenario dominates in all dimensions.

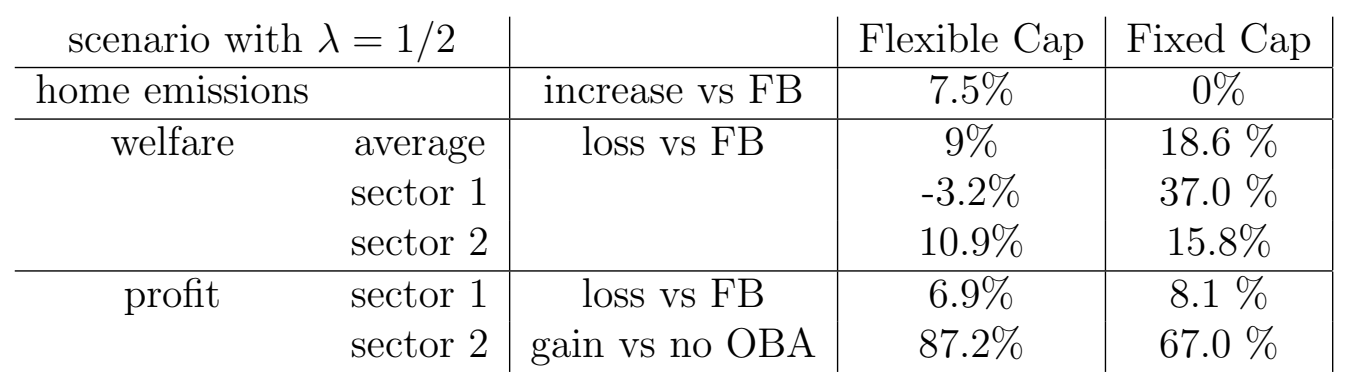

Table 1: Comparison to first best of the two scenarios

The design of an ETS is subject to political economy considerations that are outside our model. This may explain why policy makers have insisted on a fixed cap at home. It is probably easier to agree on a fixed target for 2020 than to let the actual cap depend on the OBA rates for the sectors at risk and their corresponding levels of economic activities during phase III. The commitment appears stronger than with a flexible cap (though as our illustration shows the fluctuations may be moderate and they could be reconsidered for setting a new flexible cap for the next period). However, ex-post, the commitment to a fixed cap has generated a sharp decline in the carbon price making the EU-ETS to look like "a car without an engine". As a matter of fact, a flexible cap would have led to a more stringent carbon regulation. This paradox, already pointed out in 2003 (Ellerman and Wing, 2003) should be better understood by now ${ }^{12}$

\section{Conclusions}

In a previous paper we have studied pollution permit markets in which a fraction of the permits are allocated to firms based on their output. In this paper we show that our results can be extended to the case of leakage, which for many is the primary motivation for introducing output based allocations (OBAs).

Our model provides interesting insights to discuss a number of pending issues for the design of emission trading systems in general and carbon markets in particular (e.g., Europe, California, New Zealand). A numerical illustration, motivated around discussions on how to reform the EU-ETS, is used to show the policy relevance of our results. Firstly, we show

\footnotetext{
${ }^{12}$ Ellerman and Wing (2003) compare fixed versus flexible commitments in the context of international negotiations. The flexible cap is conditioned on country GDP. No OBA are introduced. In their model the volatility of the carbon price is also reduced as one goes from a fixed to a flexible cap.
} 
that that a sector subject to demand and supply shocks should be considered as a primary criteria for using OBAs. A sector subject to such volatility should be just as eligible for OBAs as a sector with a high leakage risk but not subject to volatility.

We also show that the benefits associated with OBAs are critically dependent on the simultaneous introduction of some flexibility in the total cap at home. In the absence of this flexibility, fluctuations of the permit price would be considerably enlarged generating severe distortions in the sectors without OBAs. This may be considered as a much simpler way to control the evolution of permit prices than the complicated market-stability-reserve (MSR) approach currently followed in the EU-ETS.

Since our primary objetive was to show the role of uncertainty in the design of OBA permit schemes, some considerations were set aside during the development of our model. We see some extensions to it that can provide more precision to the numbers, but none to qualitatively change them. One possible extension is the development of a more dynamic version in which commitment periods are of limited length, as the compliance phases in the EU-ETS, with uncertainties progressively unfolding. Some limited flexibility within each commitment period may be still introduced, for example, with a price corridor, as in the Californian ETS, or with an MSR mechanism, as in the EU-ETS, or yet, with more periodic revisions of the OBA parameters (i.e. benchmarks and carbon intensities) used to compute the free allocations. The model would also benefit of more attention to short term abatement strategies, such as adapting the input mix and carbon content for electricity production, which should somehow alleviate fluctuations in the carbon price. A quantitative assessment of the results based on calibration of existing ETSs would also help. In spite of all these limitations, we think the policy claims derived from our model have some bearing for the design of current ETS policies.

\section{References}

Borenstein, Severin, James Bushnell, Frank A Wolak, and Matthew ZaragozaWatkins. 2015. "Expecting the Unexpected: Emissions Uncertainty and Environmental Market Design." Technical report, National Bureau of Economic Research.

Branger, Frédéric, Jean-Pierre Ponssard, Oliver Sartor, Misato Sato et al. 2015. "EU ETS, Free Allocations, and Activity Level Thresholds: The Devil Lies in the Details." Journal of the Association of Environmental and Resource Economists, 2(3): 401-437. 
Ellerman, A Denny, and Ian Sue Wing. 2003. "Absolute versus intensity-based emission caps." Climate Policy, 3(sup2): S7-S20.

Fischer, C., and A.K. Fox. 2007. "Output-Based Allocation of Emissions Permits for Mitigating Tax and Trade Interactions." Land Economics, 83(4): 575-599.

Fischer, Carolyn, and Alan K. Fox. 2012. "Comparing policies to combat emissions leakage: Border carbon adjustments versus rebates." Journal of Environmental Economics and Management, 64(2): 199 - 216.

Goulder, Lawrence H, Ian WH Parry, and Dallas Burtraw. 1997. "Revenue-raising versus other approaches to environmental protection: The critical significance of preexisting tax distortions." The Rand Journal of Economics, 28(4): , p. 708.

Meunier, Guy, Juan-Pablo Montero, and Jean-Pierre Ponssard. 2016. "Outputbased allocations in pollution markets with uncertainty and self-selection." Departement of Economics Ecole Polytechnique Cahier, 2016(05): , URL: https://hal.archivesouvertes.fr/hal-01321372/.

Meunier, Guy, Jean-Pierre Ponssard, and Philippe Quirion. 2014. "Carbon leakage and capacity-based allocations: Is the EU right?." Journal of Environmental Economics and Management, 68(2): $262-279$.

Monjon, Stéphanie, and Philippe Quirion. 2011. "Addressing leakage in the EU ETS: Border adjustment or output-based allocation?." Ecological Economics, 70(11): 19571971.

Quirion, Philippe. 2009. "Historic versus output-based allocation of GHG tradable allowances: a comparison." Climate Policy, 9(6): 575-592.

Schmalensee, Richard, Paul L Joskow, A Denny Ellerman, Juan Pablo Montero, and Elizabeth M Bailey. 1998. "An interim evaluation of sulfur dioxide emissions trading." The Journal of Economic Perspectives, 12(3): 53-68.

Schmalensee, Richard, and Robert N Stavins. 2013. "The SO2 allowance trading system: The ironic history of a grand policy experiment." The Journal of Economic Perspectives, 27(1): 103-121.

Weitzman, M.L. 1974. "Prices vs. Quantities." Review of Economic Studies, 41(4): 477491. 


\section{Appendix}

\section{A Linear specification and proof of Lemma 1 and Propo- sition 3}

\section{Permit market equilibrium}

Let us denote $\tilde{a}_{i}=a_{i}+\theta_{i}$ and remind that $s_{i}=1 /\left(b_{i h}\left(1-l_{i}\right)+\gamma_{i h}\right)$. Foreign production as a function of home production is:

$$
q_{i f}=\frac{\tilde{a}_{i}-b_{i} q_{i h}}{b_{i}+\gamma_{i f}}=\tilde{a}_{i} l_{i} / b_{i}-l_{i} q_{i h}
$$

Then home production satisfies the equation:

$$
\tilde{a}_{i}\left(1-l_{i}\right)-b_{i}\left(1-l_{i}\right) q_{i h}=\gamma_{i h} q_{i h}+\left(1-\alpha_{i}\right) r
$$

so that

$$
q_{i h}=s_{i}\left[\tilde{a}_{i}\left(1-l_{i}\right)-\left(1-\alpha_{i}\right) r\right]
$$

And the equilibrium permit price clears the emission permit market, i.e., $\left(1-\alpha_{1}\right) q_{1 h}+(1-$ $\left.\alpha_{2}\right) q_{2 h}=\bar{e}$, it is given by

$$
r=\frac{\sum_{i}\left[s_{i}\left(1-\alpha_{i}\right)\left(1-l_{i}\right) \tilde{a}_{i}\right]-\bar{e}}{\sum_{i}\left[s_{i}\left(1-\alpha_{i}\right)^{2}\right]}
$$

\section{Lemma 1: Choice of auctioned quantity}

From (11), 21) and (22) the optimal quantity of auctionned permits is such that

$$
\mathbb{E}(r-h)=h \sum_{i}\left(\alpha_{i}-l_{i}\right) \frac{\partial q_{i h}}{\partial \bar{e}}=h \frac{\sum_{i}\left(\alpha_{i}-l_{i}\right)\left(1-\alpha_{i}\right) s_{i}}{\sum_{i}\left(1-\alpha_{i}\right)^{2} s_{i}}
$$

therefore, at the optimal $\bar{e}\left(\alpha_{1}, \alpha_{2}\right)$ the expected permit price is given by equation (15) and, from (22), the optimal cap satisfies (14). 


\section{Proposition 3: Choice of the OBA rates $\alpha_{k}$}

Let us look at the influence of $\alpha_{2}$. We start from equation (12). From equation (21) we have that the influence of $\alpha_{2}$ on output is

$$
\frac{\partial q_{2 h}}{\partial \alpha_{2}}=s_{2} r-\left(1-\alpha_{2}\right) s_{2} \frac{\partial r}{\partial \alpha_{2}}
$$

and

$$
\frac{\partial q_{1 h}}{\partial \alpha_{2}}=-\left(1-\alpha_{1}\right) s_{1} \frac{\partial r}{\partial \alpha_{2}}
$$

from eq. 22 that its influence on the permit price is

$$
\frac{\partial r}{\partial \alpha_{2}}=-\frac{q_{2}}{\sum_{i}\left(1-\alpha_{i}\right)^{2} s_{i}}+r \frac{\left(1-\alpha_{2}\right) s_{2}}{\sum_{i}\left(1-\alpha_{i}\right)^{2} s_{i}}
$$

The derivative of welfare with respect to $\alpha_{2}$ is

$\frac{d \tilde{W}}{d \alpha_{2}}=\mathbb{E}\left\{\left[(r-h)-\sum_{i}\left(\alpha_{i}-l_{i}\right) \frac{\partial q_{i h}}{\partial \bar{e}}\right] q_{2 h}\right\}-h s_{2} \mathbb{E}\left\{\left(\alpha_{2}-l_{2}\right) r-\left(1-\alpha_{2}\right) r \frac{\sum_{i}\left(\alpha_{i}-l_{i}\right)\left(1-\alpha_{i}\right) s_{i}}{\sum_{i}\left(1-\alpha_{i}\right)^{2} s_{i}}\right\}$

Let us look at each of the terms in brackets and to ease exposition we introduce:

$$
z_{i} \equiv \frac{1-\alpha_{i}}{1-l_{i}} \text { and } \beta_{i} \equiv\left(1-l_{i}\right)^{2} s_{i}
$$

we have:

- $1^{\text {st }}$ term in brackets: using equation (11), it is shown to be equal to $\operatorname{cov}\left(r, q_{2 h}\right)$ which is, using equations 22 and 20 :

$$
\begin{aligned}
& s_{2}\left(1-l_{2}\right) \operatorname{cov}\left(r, \theta_{2}-z_{2} r\right) \\
& =\frac{s_{1} s_{2}\left(1-\alpha_{1}\right)}{\left(\sum_{i}\left(1-\alpha_{i}\right)^{2} s_{i}\right)^{2}}\left(1-l_{1}\right)\left(1-l_{2}\right)\left\{z_{1} z_{2}\left[\beta_{2} \sigma_{2}^{2}-\beta_{1} \sigma_{1}^{2}\right]+\sigma_{12}\left[\beta_{1} z_{1}^{2}-\beta_{2} z_{2}^{2}\right]\right\}
\end{aligned}
$$


- $2^{\text {nd }}$ term in brackets is equal to

$$
\begin{aligned}
& h\left(1-\alpha_{1}\right) s_{1} s_{2} \frac{\mathbb{E}[r]}{\sum_{i}\left(1-\alpha_{i}\right)^{2} s_{i}}\left[\left(\alpha_{2}-l_{2}\right)\left(1-\alpha_{1}\right)-\left(\alpha_{1}-l_{1}\right)\left(1-\alpha_{2}\right)\right] \\
= & h\left(1-\alpha_{1}\right) s_{1} s_{2} \frac{\mathbb{E}[r]}{\sum_{i}\left(1-\alpha_{i}\right)^{2} s_{i}}\left(1-l_{1}\right)\left(1-l_{2}\right)\left[z_{1}-z_{2}\right] \\
= & h^{2} \frac{s_{1} s_{2}\left(1-\alpha_{1}\right)}{\left(\sum_{i}\left(1-\alpha_{i}\right)^{2} s_{i}\right)^{2}}\left(\beta_{1} z_{1}+\beta_{2} z_{2}\right)\left(1-l_{1}\right)\left(1-l_{2}\right)\left[z_{1}-z_{2}\right] \text { using }
\end{aligned}
$$

So the derivative of welfare with respect to $\alpha_{2}$ is

$$
h^{2} \frac{s_{1} s_{2}\left(1-\alpha_{1}\right)}{\left(\sum_{i}\left(1-\alpha_{i}\right)^{2} s_{i}\right)^{2}}\left(1-l_{1}\right)\left(1-l_{2}\right)\left\{z_{1} z_{2}\left(\beta_{2} \sigma_{2}^{2}-\beta_{1} \sigma_{1}^{2}\right)+\sigma_{12}\left(\beta_{1} z_{1}^{2}-\beta_{2} z_{2}^{2}\right)-h^{2}\left(\beta_{1} z_{1}+\beta_{2} z_{2}\right)\left(z_{1}-z_{2}\right)\right\}
$$

Denoting

$$
z=\frac{z_{2}}{z_{1}}=\frac{\left(1-\alpha_{2}\right) /\left(1-l_{2}\right)}{\left(1-\alpha_{1}\right) /\left(1-l_{1}\right)} \text { and } \beta=\frac{\beta_{1}}{\beta_{2}}=\frac{\left(1-l_{1}\right)^{2} s_{1}}{\left(1-l_{2}\right)^{2} s_{2}}
$$

the sign of the derivative of welfare w.r.t. $\alpha_{2}$ is equal to the sign of

$$
z\left(\sigma_{2}^{2}-\beta \sigma_{1}^{2}\right)+\sigma_{12}\left(\beta-z^{2}\right)-h^{2}(\beta+z)(1-z)=\left(1-\frac{\sigma_{12}}{h^{2}}\right)\left\{z^{2}+z \Delta-\beta\right\}
$$

where $\Delta=\left[\sigma_{2}^{2} / h^{2}-\beta \sigma_{1}^{2} / h^{2}+(\beta-1)\right] /\left(1-\sigma_{12} / h^{2}\right)$ corresponds to the definition given by equation (18). Let us assume that $\sigma_{12}<h^{2}$. The unique positive root of the quadratics is

$$
z_{+}=\frac{1}{2}\left[\left(\Delta^{2}+4 \beta\right)^{1 / 2}-\Delta\right]
$$

The derivative of welfare w.r.t. $\alpha_{2}$ is strictly negative for $z \in\left(0, z_{+}\right)$and strictly positive for $z \in\left(z_{+},+\infty\right)$. Since an increase in $\alpha_{2}$ is equivalent to a decrease in $z$, welfare is quasiconcave w.r.t. $z\left(\right.$ or $\left.\alpha_{2}\right)$, and maximized at $z_{+}$.

Then,

- $z_{+}=1$ is equivalent to $\beta-1=\Delta$ i.e. $\sigma_{2}^{2}-\beta \sigma_{1}^{2}=\beta-1$ which proves the first point.

- $z_{+}<1$ is equivalent to $\beta-1<\Delta$ i.e. $\sigma_{2}^{2}-\beta \sigma_{1}^{2}>\beta-1$ which proves the second point.

- And setting $\alpha_{1}=l_{1}, \alpha_{2}^{*}=1-\left(1-l_{2}\right) z_{+}$prooves the last point. 